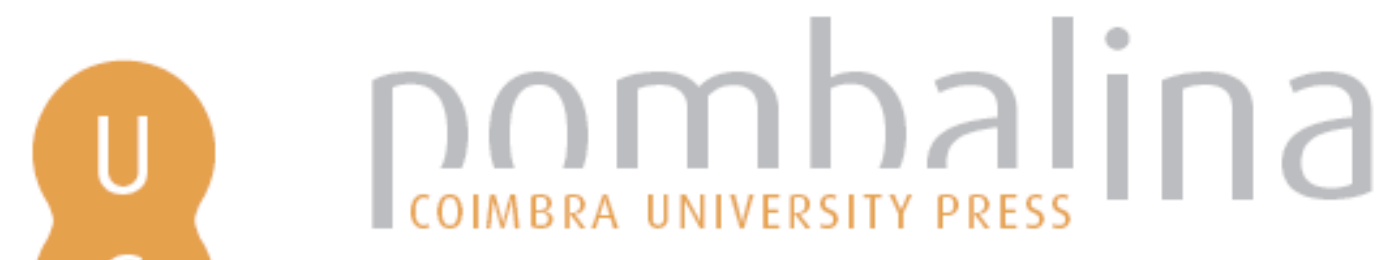

Cinema e televisão

Autor(es): Ribeiro, João

Publicado por: Imprensa da Universidade de Coimbra

URL persistente:

URI:http://hdl.handle.net/10316.2/43877

DOI:

DOI:https://doi.org/10.14195/978-989-26-1395-6_6

Accessed : $\quad$ 26-Apr-2023 07:20:25

A navegação consulta e descarregamento dos títulos inseridos nas Bibliotecas Digitais UC Digitalis, UC Pombalina e UC Impactum, pressupõem a aceitação plena e sem reservas dos Termos e Condições de Uso destas Bibliotecas Digitais, disponíveis em https://digitalis.uc.pt/pt-pt/termos.

Conforme exposto nos referidos Termos e Condições de Uso, o descarregamento de títulos de acesso restrito requer uma licença válida de autorização devendo o utilizador aceder ao(s) documento(s) a partir de um endereço de IP da instituição detentora da supramencionada licença.

Ao utilizador é apenas permitido o descarregamento para uso pessoal, pelo que o emprego do(s) título(s) descarregado(s) para outro fim, designadamente comercial, carece de autorização do respetivo autor ou editor da obra.

Na medida em que todas as obras da UC Digitalis se encontram protegidas pelo Código do Direito de Autor e Direitos Conexos e demais legislação aplicável, toda a cópia, parcial ou total, deste documento, nos casos em que é legalmente admitida, deverá conter ou fazer-se acompanhar por este aviso. 

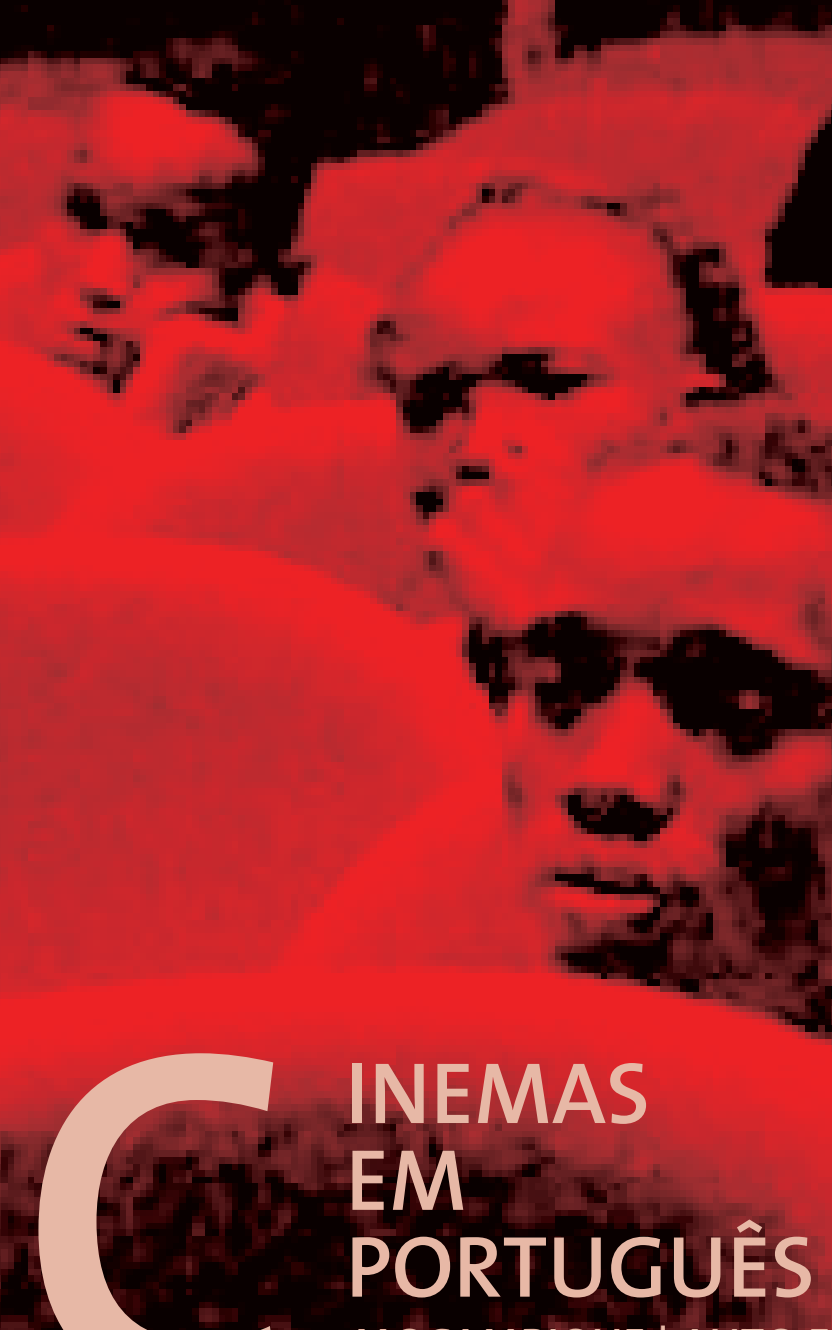

INEMAS

EM

PORTUGUÊS

MOÇAMBIQUE | AUTO E HETEROPERCEÇÕES

JORGE SEABRA

COORDENAÇÃO 


\section{CINEMA E TELEVISÃO}

João Ribeiro

Realizador | Produtor

O Cinema, depois do papel que lhe foi atribuído na $1^{a}$ República de Moçambique Independente, logo após o surgimento da TV, passou para um plano, na importância das artes, muito abaixo do $2^{\circ}$ lugar. $\mathrm{O}$ mediatismo e a magia da TV fizeram os Governos seguintes ignorar quase por completo a produção e a exibição cinematográfica.

Porém, e apesar disso, a relação Cinema-Televisão foi importante em Moçambique do ponto de vista da formação técnica e capacitação das estações de TV. Foi num momento específico, quando o INAC (Instituto Nacional de Cinema) deixou de produzir, e os seus trabalhadores, praticamente sem nenhuma ocupação, foram sendo, alguns deles, (re)enquadrados na Televisão Pública, a única então existente. Esse (re)enquadramento elevou a qualidade da produção e permitiu a formação, a outro nível, dos técnicos que na altura trabalhavam naquela estação. Por outro lado, um grande número de cineastas juntou-se e abriu a COOPIMAGEM (Cooperativa de Produção de Imagem) tendo, dessa forma, em minha opinião, lançado a produção independente em Moçambique, com pequenos documentários, maioritariamente institucionais, e fazendo filmes publicitários que eram exibidos na TV.

Surgiram a seguir outras produtoras independentes (ÉBANO MULTIMÉDIA, PROMARTE) que produziram um conjunto de importantes documentários para canais estrangeiros, num sistema que DOI: https://doi.org/10.14195/978-989-26-1395-6_6 
passava pela coprodução ou pela candidatura a concursos lançados por essas estações. Dado o estádio tecnológico em que nos encontrávamos, o que se fazia não era considerado na altura CINEMA. Eram documentários institucionais e de autor, alguns deles com um certo nível de dramatização e reconstituição, muitos de grande qualidade artística e de análise político-social. Salvo raras exceções, não chegavam à TV nacional. Ou melhor, chegavam, mas nunca eram exibidos, ou era exigido que o produtor pagasse a sua projeção através da compra de tempo de antena. Dessa forma a TV desenvolveu capacidade interna de produção própria de conteúdos alternativos para preencher a sua grelha. Porém, a TV em Moçambique nunca desenvolveu, até hoje, de forma consistente e orientada, capacidade de produção de documentários ou ficção nem, no seu todo, conseguiu criar, promover ou até mesmo estimular um sistema que permitisse uma produção regular destes géneros (ficção e ou documentário) para seu próprio consumo. Esta situação, com muito poucas e meritórias exceções, mantém-se, apesar dos 34 anos de história de TV em Moçambique e dos 12 canais em sinal aberto existentes no país.

Para complicar ainda mais a situação depois da completa paralisação das atividades do INAC - que agia como produtor, distribuidor e exibidor - o Estado alienou as salas de cinema que existiam no país, sem regular a contrapartida cultural ou impor alguma obrigação legal de exibição de filmes ou conteúdos nacionais. De um total de mais de 30 salas que antes havia, hoje apenas 3 espaços exibem de forma regular cinema comercial em Moçambique.

A televisão pública e privada ensaiou, em alguns momentos, a produção de obras de ficção e de alguns documentários. Foram pequenas séries com um orçamento modesto, muitas vezes com claras mensagens políticas ou sociais, financiadas por ONG's ou entidades estrangeiras, sempre dentro de uma estratégia de comunicação orientada para objetivos outros que não artísticos nem de desenvolvimento 
de uma linguagem de autor, de pontos de vista próprios ou da arte cinematográfica em si.

Esta posição assumida pelos canais de TV, combinada com a degradação e consequente paralisação da exibição em sala, provocou uma enorme lacuna no horizonte cultural nacional e no seio do ainda pequeno grupo que se havia criado a partir do INAC, que se via assim impossibilitado de desenvolver projetos próprios.

Com o desenvolvimento das novas tecnologias e o surgimento de meios de produção alternativos, os cineastas puderam voltar a produzir os seus próprios projetos, apesar das restrições à exibição prevalecentes. Passou a haver uma espécie de produção militante que, em jeito de vingança, digamos, usava a capacidade desenvolvida pela televisão, aquela que havia de certa forma "travado" a produção cinematográfica, para voltar a fazer cinema.

Pouco depois dos anos 90 aparecem projetos de curtas e longas de ficção que, alavancados pela produção portuguesa que chega a Moçambique através de financiamentos à produção do Instituto de Cinema (Portugal), voltam a acender a luz no fundo do túnel. Os filmes produzidos nesta fase nunca chegam à Televisão e a dificuldade relativa à sua exibição é agravada pelas difíceis condições de circulação rodoviária, e de outras infraestruturas para que haja exibições alternativas. Dessa forma, apesar do aumento da produção cinematográfica nacional, continua muito pequena a penetração do "cinema" nacional junto do público que, em sentido contrário, é cada vez mais exposto à produção de novelas, shows musicais e reality shows à moçambicana, que a partir de 2002 começam a povoar o horizonte cultural e a ser referência obrigatória.

Portanto, apesar do grande incremento da produção de cinema e dos filmes rodados em Moçambique por produtores europeus e americanos, e não obstante o notório esforço de produção empreendido pelos produtores independentes (nunca o Estado ou o sector regulador da atividade), o Cinema perdeu posição face à Televisão. 
Passou também a Televisão a formar os seus próprios técnicos em edição e câmara, em realização de programas e em iluminação e som, técnicos esses que, embora de deficiente qualidade e conhecimento, começaram a aparecer em produções de "cinema", ocupando o espaço criado pelos ainda "cineastas".

De 2008 a 2011 acontece o melhor momento da produção do Cinema em Moçambique dos últimos tempos, com a realização de várias longas-metragens nacionais e estrangeiras em simultâneo. $\mathrm{O}$ ambiente é bastante positivo e a expectativa é grande. Mas, contra as expectativas geradas por estas oportunidades, a falta de políticas para o sector e a corrupção em alguns segmentos da cadeia de valor da produção, que passaram a gerar intrincados processos para a obtenção de autorizações e licenças, fazem retroceder todo este desenvolvimento, a ponto de parar completamente a produção de cinema no país. Em paralelo, a TV nacional continua a produzir os seus talk-shows e reality-shows adaptados, e a produzir as suas "estrelas", coisa que o Cinema em Moçambique ainda não conseguiu fazer. Os nossos atores são conhecidos pelas suas participações em peças de teatro, pela sua exposição na TV e na imprensa escrita. Pelo contrário, os realizadores de cinema (com raras exceções), os atores e os autores que para ele escreveram continuam desconhecidos do público.

Nos dias de hoje, a inexistência de leis e a fraca regulamentação existente sobre o processo de obtenção de licenças para exploração de canais de TV em Moçambique, deixa espaço para uma exibição de conteúdos sem qualquer controlo que não seja o político (controlo esse sempre exercido à margem da Lei e de forma ambígua, fazendo-se sentir, por exemplo, através do corte de financiamentos, redução de publicidade, ações de inspeção e de fiscalização). A falta de obrigatoriedade de proteção e valorização do conteúdo nacional e a inexistência de plataformas de apoio e captação de receitas para o incentivo da produção audiovisual não facilitam a 
produção de conteúdos de autor, nem a valorização de histórias e autores nacionais.

Não temos ficção na TV, não temos produção de ficção fora dela. Não temos documentários nacionais na TV, e a produção de documentários independentes sujeita-se à participação em difíceis e muito competitivos concursos internacionais, ou a algum trabalho comissionado por "clientes" institucionais públicos ou privados.

Com o aparecimento do multimédia, e uma vez que as etapas anteriores de desenvolvimento de formatos e géneros na ainda precoce cinematografia moçambicana estavam por concluir, e com apenas 3 locais de exibição sistemática de cinema (sempre o blockbuster americano), não temos ainda "modelos de produção" estabilizados em Cinema e Televisão, nem conseguimos criar as referências fundamentais para a continuidade e para o crescimento de uma cinematografia autenticamente moçambicana.

A Televisão, pela sua abrangência e efeito psicológico sobre as massas, deveria ser o catalisador da vontade para se ter o embrião de um star system, de uma cadeia de valor que fosse profissionalizando a produção cinematográfica e, mesmo que pequena, caminhasse numa relação de procura e oferta dentro dos limites do possível. O desenho de uma política cultural a médio prazo seria um posicionamento claro do interesse do Estado na promoção das artes onde o Cinema ganharia valor. A ausência de tudo isto e as tentativas de valorização da autoestima tão promovida no último regime, intrinsecamente ligada à obtenção de ganhos financeiros e de ascensão social, debilitaram profundamente o tecido social e, consequentemente, a arte e a cultura passaram a planos ainda mais secundários na longa lista de prioridades do Governo.

É possivelmente devido a todos estes fatores que se pode constatar a ausência de um trabalho de análise, dentro do território nacional, das diferenças estéticas, temáticas e de produção entre o Cinema e a Televisão. E, se o cruzamento destas formas de estar e fazer aconte- 
ceu paulatinamente em países mais desenvolvidos (contrariamente à inserção das tecnologias que foram e continuam a ser assumidas entre si com uma rapidez incrível), se longas discussões foram abertas e muitas filosofias criadas e analisadas sobre a prevalência e capacidade de sobrevivência de cada uma delas - Cinema e Televisão -, em Moçambique, anárquica e incoerentemente, sem qualquer orientação, uma suportou a outra, garantindo que, de algum modo, se continuasse a ter produção audiovisual no país. 